\begin{tabular}{|c|l|}
\hline Title & Resident's concerns and attitudes towards Solid W aste Management facilities \\
\hline Author(s) & Rahardyan, B.; Matsuto, T.; Kakuta, Y.; Tanaka, N. \\
\hline Citation & $\begin{array}{l}\text { Waste Management, 24(5), 437-451 } \\
\text { https://doi.org/10.1016/.wasman.2003.11.011 }\end{array}$ \\
\hline Issue Date & 2004 \\
\hline Doc URL & http://hdl.handle.net/2115/13712 \\
\hline Type & article (author version) \\
\hline File Information & wm2004rahardy an.pdf \\
\hline
\end{tabular}

Instructions for use 


\title{
Resident's concerns and attitudes towards Solid Waste Management Facilities
}

\author{
B. Rahardyan ${ }^{\mathrm{a}}$, T. Matsuto ${ }^{\mathrm{a}, *}$, Y. Kakuta ${ }^{\mathrm{b}}$, N. Tanaka $^{\mathrm{a}}$ \\ ${ }^{a}$ Laboratory of Solid Waste Disposal Engineering \\ ${ }^{\mathrm{b}}$ Recyclable Resources Assessment (TAKUMA Endowed) Laboratory \\ Hokkaido University, Kita 13 Nishi 8, Kita Ku, Sapporo 060-8628, Japan
}

* Corresponding author.

Tel.: +81-11-706-6828; fax: +81-11-706-6828

E-mail address: matsuto@eng.hokudai.ac.jp (T. Matsuto) 


\section{Abstract}

Because of limited space, the siting and construction of a new SWM facility is a big challenge in Japan. An SWM facility should be socially accepted as well as environmentally and economically sound. This study aimed to investigate people's concerns about SWM facilities and their attitudes towards such facilities. A questionnaire was designed based on literature reviews and was sent to residents in three municipalities with different backgrounds. The questions covered concerns on the impact of an SWM facility, management aspects, unfairness of facility siting, and attitudes to facility construction.

Of the many concerns, "pollution and health effect" had the highest rating, followed by "reliability", "damage to nature" and "cost". The rating was different between municipalities, reflecting their geographic and social backgrounds. Using factor analysis, correlations among concerns were analyzed, and five principal components were extracted, namely "pollution", "nuisance", "facility management", "planning of facility", and "merit/demerit". Although obvious correlations were not found between individual items of concern and attitudes to construction of a facility, the discriminant analysis indicated dominant concerns of attitudes, but the disagreement between actual impact and citizens were found. As for attributes, the "opposed" attitude decreased for residents who had visited an SWM facility, even if they had only seen it from outside.

Keywords: Solid waste management (SWM), resident, concern, attitude, SWM facility 


\section{Introduction}

Solid Waste Management (SWM) is a major part of the social system. In Japan, to realize a "Resource recycling society" minimizing environmental impact and resource consumption, various laws and guidelines have been issued based on the 3R principles, i.e. Reuse, Reduce, and Recycle. These $3 R$ activities will reduce the volume of waste, but cannot eliminate it. Therefore, there is still a need for appropriate disposal methods for residual waste. Limited siting space is a major challenge when constructing a new facility, and social acceptance by neighbors is another. To be accepted, an SWM facility should be environmental friendly, economically sound, and socially acceptable. An SWM facility that is not accepted may be opposed (Furuichi, 1999). Social movements and conflicts between residents and an authority sometimes lead to closure of an existing facility (Been, 1993). Especially in Japan, where SWM facilities are usually located near residential areas, the opposition of residents is a vitally important issue in solid waste management.

To increase people's acceptance level of an SWM facility, dialog with neighbors or public involvement in the planning stage is has become popular in recent years, and these procedures are widely discussed. For better communication with citizens, it is essential to understand people's concerns and concepts of SWM management facilities. This is also essential for better SW management practice.

The objective of this study was to investigate people's concerns about SWM facilities, and make clear which concern is the most influential to attitudes towards such facilities. For this purpose, firstly, key variables (concerns) were extracted by literature review, and then a questionnaire structure was designed. Secondly, priorities among concerns and their inter-relations were identified. Thirdly, the relation between identified concerns and attitudes toward SWM facilities were analyzed, as well as the relation with personal attributes.

\section{Reviews of citizen's concern towards SWM facilities}

In order to extract concerns influencing people's attitudes towards and the acceptability of an SWM facility, existing literature on the subject was reviewed. Because there are only a limited number of studies regarding solid waste management and disposal, literature on the general environment was also collected. 


\subsection{Influential concerns on attitude}

Zeiss (1991) proposed consecutive linkage starting from physical impacts to beliefs, and finally to attitudes. He classified impacts into two categories: physical and non-physical. Physical impacts include health risks, nuisances, and environmental change, and these in turn generate non-physical impacts, which are categorized into economic (e.g. property value decrease), social (community image loss), and political (e.g. lack of fairness) impacts. Fears about physical impacts are usually exaggerated by residents and do not correspond to actual damage, and non-physical impacts affect attitudes as strongly as physical ones. Therefore, a minor physical impact may trigger a very strong negative attitude to an SWM facility.

In terms of physical impacts, pollution causes psychological stress and fear of health risks (Petts and Eduljee, 1994; Becker, 2001). As Lima (1996) mentioned in a study related to an incinerator, perception of risk is a factor in changing attitudes, and a risk is considered greater when the hazard is involuntary and uncontrollable, not natural, and cannot be compensated for by any benefits (Petts, 1994).

Petts (1994) suggested that citizens' attitudes are influenced not only by impacts, but also by a lack of credibility in waste managers, decision makers, decision processes, and control mechanisms for waste facility siting and operation. Without a clear or open decision making process, siting of undesirable facilities becomes an extremely difficult task (Opaluch, 1993).

Besides negative impacts, there are positive aspects of an SWM facility. The benefit a facility may bring to local residents can influence attitudes (Lima, 1996). For example, residents who have an incinerator in their community think it is a better disposal facility than a landfill due to the heat supply service it provides to its surrounding area.

Citizens' attitudes depend on knowledge about a facility. Zeiss (1991) mentioned that residents tend to show more negative attitudes to unfamiliar facilities of which they have no experience, compared with similar facilities that already exist. As a factor of personal background, educational level is also influential. 


\subsection{Main concerns about SWM}

Citizens' concerns relevant to acceptance or attitude to an SWM facility, as obtained through literature reviews, are summarised in Table 1. Since there was a great diversity of terminology, similar words and expressions are integrated, and gathered into several groups.

Among physical impacts, pollution and its health effects was undoubtedly one of the most important concerns regarding solid waste. Air, surface water, groundwater, and soil are major polluted media, and there are various pollutants ranging from organic material to hazardous chemicals. Influence on the environment is also considered, including effects on wildlife, forest destruction, and land conversion.

Physical impacts create a nuisance, but this is more of an emotional effect than actual pollution. The physical impacts take various forms: odor, noise, vibration, litter, and "pests" such as flies, rodents, and crows. Greater volume of traffic because of collection vehicles, and the possibility of car accidents are also potential causes of nuisance. Non-physical impacts, such as impairment of landscape or views by an SWM facility, and a decrease in property value can be categorized in the nuisance group.

The fear about risks increases when information about the SWM facility is limited. The lack of information also decreases the credibility of a facility owner (usually local government in Japan), and leads to protests to the facility. Therefore appropriate information disclosure is an important factor for acceptability and for avoiding disproportionate facility siting (Tchobanoglous, 1993).

As for positive impacts of the SWM facility, there is an increase in employment opportunities (Petts and Eduljee, 1994), financial compensation (LSA, 1999), and services provided by the facility such as heat supply (Hoshino, 2001).

In Table 2, factors influencing personal judgment of SWM facilities are summarized. These are divided into personal factors and demographic factors, but the latter are not discussed in this paper. 


\section{Methodology}

\subsection{Structure of Questionnaire}

Based on the literature review mentioned above, the questionnaire was designed to assess people's concerns and attitudes to SWM facilities. It was made up of four parts as shown in Table 3. The first three parts were questions to ascertain the degree of concern on various aspects of SWM, and the fourth part asked about attitudes. In the later section, concerns in the 1st and 2nd parts were analysed for their interrelation and correlation with attitudes, so these were called concern variables or variables in the following context. Each question was identified with a number from Q1 to Q33. Before starting to answer, each respondent was asked to suppose that an SWM facility (an incinerator, a landfill, a recycling facility etc.) had been constructed in his/her town. The type of facility was not specified.

The first part (Q1 to Q13) included questions to discover the extent of people's concerns about impact or damage caused by an SWM facility. This part had three sub-groups of questions. In the "pollution and health effect" question, "dioxin" was added because it has been a special concern among citizens in recent years in Japan, where eighty percent of municipal solid waste is incinerated. "Damage to the environment" was aggregated into "plant \& animal", and "forest". In the "nuisance" group, besides the impacts mentioned in section 2, "influence on farm products" was added considering the fact that vegetable sales fell because of rumors of dioxin pollution in a city near Tokyo several years ago. These concern issues were rated into four scales from "very worried", "worried", "slightly worried", and "not worried at all". A "Not sure (NS)" option was also provided in the answer sheet.

The second part (Q14 to Q21) was made up of questions regarding the management aspect of an SWM facility. It was divided into three aspects, "benefit", "reliability", and "cost". The financial stability of the facility owner was added in the "reliability" group considering the case of industrial waste disposal facilities run by the private sector, because bankruptcy of an SWM company would cause fears of improper disposal of waste. However, most citizens are unlikely to think of industrial solid waste management when asked about SWM. "Initial cost" and "OM (operation and maintenance) cost" were also added because the expense of solid waste management is met by regional tax. "Post- 
closure property value", only relevant to landfill, was also added to the question. These questions were rated in a four-grade scale from "very important" to "not important at all".

"Unfairness of siting of an SWM facility" was assessed in the third part (Q22 and Q23). Two cases were assumed. One concerned unfairness in receiving waste from other cities and towns, and the other was about construction of an SWM facility to dispose of waste generated in the town or city in the respondent's community. In Japan, most municipalities treat and dispose of municipal waste generated in their own facilities, so the former situation is not common and is likely to be opposed by residents. These questions were answered in a four-grade scale between "very unfair" and "not unfair at all".

In the fourth part (Q24 to Q29), questions regarding attitudes toward solid waste treatment facilities were asked. Assuming the case that construction of an incinerator, a landfill, or a recycling facility was planned $1 \mathrm{~km}$ away from the respondent's residence, his/her attitude was rated as either "in favor", "not concerned", or "opposed". Regarding general attitudes toward waste and recycling, the questionnaire investigated the image of waste, concerns about recycling activities, and willingness to participate in waste management planning. The former two questions answered in four-grade scales, and the latter was answered by "yes" or "no".

Finally, personal attributes such as "years at current address", age, sex, and additionally, "experience of visiting an SWM facility" were asked (Q30 to Q33). In Q33, the type of facility was not specified in the question.

\subsection{Scheme of this study}

The structure of this study is schematically shown in Figure 1. In section 4.1, the degree of concern for each impact is compared. In 4.2, factor analysis is performed to distinguish principle components or integrated factors for people's concerns about an SWM facility. Section 5 is devoted to analyzing the relationship between concerns and attitudes toward SWM facilities. In 5.1 and 5.2 , the degree of concern was compared among different attitude groups, and the difference is statistically tested. Discriminant analysis is used to identify influential factors on attitude in 5.3. Finally, in 5.4, Correspondence analysis is used to describe the relation between attributes of respondents and their attitudes. 


\subsection{Surveyed municipalities}

The questionnaire shown in Table 3 was sent to residents of three municipalities, Sapporo, Hinode, and Kutchan. These places were chosen for the following reasons.

The town of Hinode (population 16,000), which is located in the suburbs of the Tokyo metropolitan area, has a regional landfill to receive municipal solid waste from surrounding municipalities. After a leak of leachate into the groundwater was suspected in 1990, a citizens' group demanded that the managing administrative body release monitoring data, and the group continued to protest against the construction of a second landfill next to the first one. Hinode is an example of a municipality having trouble with waste.

Kutchan is a rural town of 16,000 people in Hokkaido. The town is famous for distributing detailed information on source separation. That is, the town distributes leaflets to residents in which collection categories and instructions for pre-treatment are tabulated for 1300 kinds of waste items. Kutchan is one of the most enthusiastic towns for waste management and recycling.

Sapporo is the capital city of Hokkaido, having a population of 1.8 million. It does not have serious problems related to solid waste because it has affordable space, and has several advanced recycling facilities in a so-called recycling complex, such as an RDF plant, fish food production (FFP) facility from food waste, and a pyrolysis plant for waste plastics (although the RDF and FFP plants dispose of business and commercial waste). Sapporo is considered an average city in terms of household waste recycling.

From a telephone directory of each city, fifty names were randomly extracted. Despite the disadvantage that not all residents were listed in the directory, this approach was used for the ease of selecting respondents in different cities. The questionnaire was sent in October 2002, and collected by enclosed, pre-paid return envelope.

\subsection{Outcome}

Overall recovery of the questionnaire was $34 \%$, and most were sent back by respondents after two weeks. The highest recovery rate was $42 \%$, from Sapporo, while the rates for Kutchan and Hinode were $30 \%$. The data were collected on spreadsheets and analyzed using simple statistical 
techniques. SPSS 10.5 was used for further analysis, i.e. for factor analysis, correspondence analysis, and discriminant analysis.

Respondents' attributes (Q30 to Q33) and attitudes to general questions (Q27 to Q29) are summarised in Figure 2. Respondents were generally male, aged over 40, who had lived for 10 years or more at their current address. The large percentage of males was unavoidable because the husband's name is usually registered in the telephone book. In addition, young people tend to be unwilling to list their names in the book, and low return rates for this kind of survey are expected. The highest percentage of females came from Sapporo with a rate of almost $20 \%$, while in Hinode, $100 \%$ of data were from males. The result showing that more than half the respondents had visited an SWM facility (Q30) was surprising, and a similar trend was also seen in general questions. That is, in total, 70 percent of residents were willing to participate in SWM planning (Q29). These ratios suggest that environment-conscious people responded to the survey. The lower score for participation in planning in Hinode seems to reflect the history of SWM as cited in the previous section. Concern for recycling was high at around 80\%, and solid waste did not have such a bad image (Q27).

Results for questions about unfairness of siting of an SWM facility (Q22 and Q23) are also shown in Figure 2. Higher percentages of people thought it was unfair to receive waste from other municipalities (Q22) than was the case for having an SWM facility in their neighborhood (Q23). The difference in feeling was large in Hinode, which suggests that people were more sensitive about receiving somebody else's waste than other surveyed municipalities. Kutchan showed no difference between the two cases.

\section{Concerns about SWM facilities}

\subsection{Comparison of concerns}

In Figure 3, concerns about impacts (Q1 to Q21) are compared among three surveyed municipalities. For each question, the answer was rated with 3 to 0 scores: e.g. "very worried "was rated as 3, and "not worried at all" was 0 . "Not sure" and no answer were excluded when taking an average for each municipality. In each sub-group of concerns, concerned items were arranged in the order of an overall average score. 
From the comparison of six sub-groups, "pollution and health effect" had the highest rating, and were followed by "reliability", "damage to nature" and "cost". However the difference was not so obvious. This means that people's concern ranged over various aspects and was not limited to a specific object. In "nuisance", "flies, rodents, and crows" was the strongest concern, rating as high as the top groups, while "decrease of property value" was the lowest among all concern items. The rating of "benefit" was low.

When scores were compared among municipalities, Hinode had higher ratings than the others in most concern items except for "benefit". In a city receiving other city's waste, such higher attention is understandable. There were especially high ratings for "reliability" and "cost". Meanwhile, Kutchan showed the lowest value for most items but especially for "nuisance", which seems to reflect low environmental pressure in rural areas. Concerns for "reliability" and "cost" in Sapporo were as low as in Kutchan. The higher rating for "benefit" was because the heat supply to the surrounding community from the incinerator is advantageous in this cold area.

\subsection{Factor Analysis}

Factor analysis was used to uncover a latent structure of concern variables in Q1 to Q21. After excluding data (persons) missing or "Not sure" answers, data from 32 people were used for the analysis. Although the amount of data was not large enough for the number of variables (Q1-Q21), for the purpose of finding a correlation among variables and of selecting key variables in future study, all concern variables were used for the analysis. As a result, five principal components (or factors) were extracted by the principal component method with varimax rotation. Component loadings are shown in Table 4. Loadings above 0.6 are usually considered "high" and those below 0.4 are "low. In Table 4 , 0.5 was used as a criterion, and variables are arranged in the order of component loading in each factor. Component loadings are plotted also in Figure 4.

The first component can be termed the "pollution" factor because "air, water, soil pollution (Q1-Q3)" and "dioxin(Q4)" were included in this group. "Deterioration of living environment (Q11)" was also identified in this component, so these impacts were considered similar by citizens.

The second component can be called the "nuisance" factor. "Damage to nature (Q5,Q6)" was categorized into the first component in terms of factor loadings, but was close to the "nuisance" 
component as seen in Figure 4. "Stench and noise (Q7, Q9)" also had high loadings in the first component. Therefore, "pollution" and "nuisance" considerably overlap with each other. On the other hand, "Reliability of technology (Q16)" was located between the 2nd and 3rd components. The third component comprised "cost (Q19, Q20)" and "information disclosure(Q15)". When including "reliability of technology", this was related to "facility management".

The fourth and fifth components were hard to name because different aspects were included. The fourth component included "clear siting process (Q18)" and "financial stability(Q17)", so it is related to "planning". The fifth component includes "convenience by facility (Q14)" and "decrease of property value(Q12)" is close to this component. This is called the "merit/demerit" component.

\section{Attitude toward SWM facilities}

\subsection{Relation with concerns}

The relation between attitudes toward construction of SWM facilities (Q24 to Q26) and degree of concern (Q1 to Q21) was studied. The opposition rate, which was calculated as the ratio of "opposed" to "opposed"+ "in favor" in the number of respondents excluding "not concerned", was 0.625-0.75 for an incinerator, $0.73-0.86$ for a landfill, and $0.2-0.4$ for a recycling facility for three municipalities. Because these differences were not statistically significant, an overall rating was used in this analysis. In Figure 5, an average rating for each concern variable is plotted for each different attitude group. Concern variables are aligned in the order of question here, and the numbers of respondents are shown in the figure.

On the whole, scores of the "not concerned" group were lower than for the other two groups. This means that people who don't have a clear attitude toward an SWM facility are those who have less concern about pollution and nuisance. Meanwhile, the difference between the "opposed" and "in favor" groups were generally not remarkable, but wide differences were found for some impacts, such as "nuisance" for a recycling facility and for a landfill. More detailed discussions will be done in later sections. The "opposed" group for a recycling facility, which is considered a less undesirable facility than an incinerator or a landfill, may have been composed of people worried about almost everything and who did not want any foreign facility. 


\subsection{Association analysis between attitude and concern}

Goodman-Kruskal Gamma is used to measure the relationship between two variables. It is a kind of a correlation coefficient for qualitative variables, producing a value between -1 to 1 . Giving a value of 1 to "in favor" and 0 to "opposed", and excluding people who answered "not concerned", GK gamma was calculated for a combination of attitudes to each facility and concern variable. If the value was negative, higher concern was supposed to lead to the opposing attitude. The result is shown in Table 5. The result of a Chi-square test is also shown in Table5. In the Chi-test, the choice for concern was grouped into two categories, namely "very", and the other choices (because the number of answers between "worried" to "not worried at all" were small).

As seen in Table 5, "stench and noise" and "traffic accidents caused by collection vehicles" were found to have a correlation with attitudes to a recycling facility. This implies that these minor impacts could provide a reason for opposing an SWM facility for some people. For landfill, "information disclosure on operation and management" was the only variable that had a correlation with attitude. There was no significant relation found for incinerator. There was no correlation identified by the Chi-test. However, this analysis was just simple correlation, so a more detailed analysis will be carried out in the next section.

\subsection{Discriminant analysis}

To find influential concern variables on attitudes to SWM facilities, discriminant analysis was applied. In this method, a discriminant function is formed as a linear combination of variables, in a similar form to a multi-regressional equation, to predict the group to which each sample belongs. To maintain the independence of variables, correlated variables that were found in Figure 4 as a result of factor analysis were combined, and average scores were used. Items of concern in Q15 to Q21 are relevant to management of an SWM facility and not directly related to the type of facility; therefore they are not used as independent variables. In the analysis, personal data showing an attitude of "in favor" or "opposed" were used (excluding "not concerned" answers), and a positive value was given to the "in favor" attitude and a negative value to "opposed" as objective variables. The standardized coefficients of the discriminant functions are shown in Figure 6 . If the value of the function was positive, the respondent was judged to be in the "in favor" group, and vice versa for the "opposed" 
group. The prediction was $72 \%$ correct for incinerator, $65 \%$ for landfill, and $73 \%$ for recycling facility. Since the coefficients of the function depend on a selection of variables, several sets of variables were attempted in order to ensure the validity of the result.

The highest negative value was seen in dioxin for both incinerator and landfill, and damage to nature and the environment ("stench and noise" were included) were followed. The positive value of "deterioration of living environment" for landfill was unstable depending on a selection of variables. Meanwhile "air, water, and soil pollution", and "flies, rodents, crows" had positive values or had a lesser contribution. It is suggested that these items were ones of great concern to residents as seen in Figure 3, but SWM facilities were not worried to cause such impacts. "Convenience of facility" had a positive coefficient, and the lower value for incinerator might be due to the relatively large value for pollution.

As Zeiss (1991) mentioned, a disagreement between actual damage and the citizens' belief were found in this study, such as with the positive values of pollution and the negative value of dioxin from landfill. This indicates that appropriate information on SWM is essential for better understanding.

\subsection{Influence of respondent attributes to acceptability of SWM facilities}

\subsubsection{Correlation with personal attribute}

Correlation of personal attributes (Q31 to Q33) with attitude was analyzed by correspondence analysis. This is a principal component analysis of qualitative (categorical) data, and it can show the similarity of response in two or more dimensional space. In this analysis, respondents who had missing values, i.e. no answer or a "Not sure" answer, were excluded. The relation with "experience of visiting an SWM facility" (Q30) is discussed in 5.4.3 later.

Figure 7 shows the results for relation with personal attributes. The numbers of respondents are shown in parenthesis. The "opposed" attitudes to three facilities are plotted closely to each other, as are the "in favor" attitudes. From the positions for these attitudes in $x-y$ plane, $x$-axis was considered as the "opposed-in favor" attitude, and y-axis means the "not-determined or not concerned" attitude. 
Attributes close to "opposed" groups are "aged in their 40s and 50s" who had lived 10 to 20 years at their current address. On the other hand, older people tended to show "in favor" attitudes or "not concerned" attitudes, while young people showed less concern about SWM facilities.

\subsubsection{Correlation with general attitudes}

Figure 8 examines the relation with consciousness of unfairness (Q22,Q23) and general attitudes (Q27 to Q29). Respondents whose answer or attributes were small in number were also excluded because their uniqueness would have disturbed the analysis by extracting components only to explain the uniqueness. "Not dislike at all" and "Not unfair at all" were excluded for that reason. Attitudes of "opposed", "in favor", and "not concerned" are similarly plotted as in Figure 7, so the $x$ and $y$ axis represent the same meanings. Since "not participate (in planning)", "very unfair" for two cases of SWM facility siting, and "disliked waste very much" are close together and plotted close to the "opposed" attitude, they are strongly correlated with the "opposed" attitude to SWM facilities. On the other hand, "participate in planning" and "concerned very much about recycling" are plotted close to the "in favor" attitude.

\subsubsection{Correlation with experience of visiting a facility}

The relation with "experience of visiting an SWM facility (Q30)" is shown in Figure 9, aside from other attributes, because there were clear tendencies with attitude. For each facility, while all residents showed an "opposed" attitude if they had never visited SWM facilities, the "in favour" attitude increased dramatically for people who had made such visits. Slight increases were seen even for respondents who had only noticed or seen SMW facilities from outside. This result suggests that unknown facilities tend to be opposed; a fact mentioned by Zeiss (1991). This underlines the importance of communication with residents in the case of new facility siting.

\section{Conclusion}

In this study, people's concerns towards SWM facilities and their relation with attitudes to facilities were analyzed. A questionnaire was designed based on major concerns of citizens extracted from literature reviews. These concerns were integrated into twenty- three questions: 13 were related 
to impact by a facility, 8 were related to the management aspect, and 2 questions concerned unfairness of siting of a facility. Six questions were asked on attitudes towards construction of a facility, and attitudes to general aspects. Questionnaires were sent to residents in three municipalities that had different backgrounds of waste management and geographic conditions. The main results were as follows.

1) The highest concern was found on the "pollution and health effect", followed by "reliability", "damage to nature" and "cost". However, the difference between these was not so obvious, so people's concern was not limited to a specific object but covered various aspects. The categories of "nuisance", "flies, rodents, and crow" showed the highest levels of concern, while "decrease of property value" was rated low. (4.1)

2) Ratings of concerns were different among the surveyed municipalities, and this reflected their background. Ratings were generally higher in Hinode, which receives other city's waste, and which had a conflict between a citizen's group and management body. Kutchan, a rural town, showed the lowest value for most items, especially for "nuisance", which seems to reflect low environmental pressure. (4.1)

3) Using factor analysis, five principal components were extracted. They were named "pollution", "nuisance", "facility management", "planning of facility", and "merit/demerit". Judging from factor loadings, "damage to nature" was conceived both as "pollution" and "nuisance", while "stench and noise" were categorized in "nuisance" but also had high loading in "pollution". The first and second components overlapped with each other. (4.2)

4) In terms of attitudes, the "not concerned" group showed a lower rating of concerns than the "opposed" and "in favor" groups. This suggests that people who did not have a clear attitude toward SWM facilities were those who had less concern about impacts of the facility. Meanwhile the difference between the "opposed" and "in favor" groups were generally not remarkable. (5.1)

5) According to Goodman-Kruskal gamma and chi-square tests, there was no simple correlation between concern and attitude except for a couple of combinations. (5.2)

6) Discriminant analysis was applied for "in favor" and "opposed" groups. After combining correlated variables to maintain the independence of variables, "dioxin" and damage to nature had 
contribution to "opposed" attitude, but the disagreement between actual damage and citizen's belief were found. (5.3)

7) As for personal attributes, "opposed" groups were identified as comprising people "aged in their 40 s and 50s" who had lived 10 to 20 years at their current address, and they also showed negative attitudes to other aspects: not participating in planning, feeling a strong unfairness about facility siting, dislike waste very much. $(5.4 .1,5.4 .2)$

8) Respondent's attitudes were obviously correlated with experience of visiting an SWM facility. The "opposed" attitude decreased for people who had made such visits and a slight decrease was found even for respondents who had only noticed or seen an SMW facility from outside. This result suggests that unknown facilities are susceptible to opposition. (5.4.3)

\section{Acknowledgement}

The authors gratefully acknowledge the support of Recyclable Resources Assessment (Takuma Endowed) Laboratory University for this research. We wish to thank Ms. Y. Fujimoto for conducting survey and data preparation. 


\section{References}

Becker, H., 2001. A Social Impact Assessment, European Journal of Operational Research, Vol. 128 (2) $311-321$.

Been, V., 1993. What's fairness got to do with it? Environmental justice and the siting of locally undesirable land uses, Cornell Law Review, http://www.nyu.edu/pages/elc/ej/BEEN/CornellTOC.html\#fno

Furuichi, T. (ed), 1999. Planning of solid waste management, Kyouritsu, Tokyo, 74 (in Japanese)

Garrod, G.D., and Willis, K., 1998. Estimating lost amenity due to landfill waste disposal, Resources, Conservation and Recycling, 22, 83-95.

Hoshino, T, Shimada, Y., Funawatashi, F., 2001. Comparative analysis of the resident consciousness around the different waste incinerators, Journal of Environmental Information Science, 151 67-72 (in Japanese)

Lima, M. L., 1996. Individual and social determinants of attitudes towards the construction of waste incinerator: two case studies, The 1996 Annual Meeting of the Society for Risk Analysis-Europe, The Centre for Environmental Strategy, University of Surrey, Guildford, Surrey

Landfill System Technologies Research Association (LSA), Handbook for solid waste landfill technology system, Kankyo-Sangyo-Shinbun, 1999 (in Japanese)

Opaluch, J. J., Swallow, S.K., Weaver, T., Wessels, C. W., Wichlens, D., 1993. Evaluation Impacts from noxious facilities: including public preferences in current siting mechanisms, Journal of Environmental Economics and Management 24, 41-59.

Petts, J., 1994. Effective Waste Management: Understanding and Dealing with Public Concerns, Waste Management \& Research, Vol. 12 (3) 207-222.

Petts, J. and Eduljee, G., 1994. Environmental Impact Assessment for Waste Treatment and Disposal Facilities, John Wiley \& Sons, Chichester, U.K.

Slovic, P., 2000. The perception of risk, Earthscan Publications, London

Tchobanoglous, G., Theisen, H., Vigil, S., 1999. Integrated solid waste management: engineering principles and management issues, McGraw-Hill, Singapore

Zeiss, C. and Atwater, J., 1991. Waste Disposal Facilities and Community Response: tracing pathways from facility impacts to community attitude, Can. J. Civ. Eng. 18, 83-96 
Table 1 Factors related to citizen's acceptance of SWM facilities

Pollution and its health effects

- Fear of pollution occurrence

- Fear of risk (Becker, 2001)

Damage to Environment

- Influence on flora and fauna / wild life

- Conversion of the environment

Nuisance

- Odor

- Vibration

- Noise

- Dust and litter

- Vector insect \& pest

- Impairment of landscape and view

- Decrease of property value
Convenience of facility

- Public services such as heat supply

- Community facility

- Employment

Information Disclosure

- $\quad$ Chance of community involvement (Tchobanoglous, 1993)

- Accessibility to information

Reliability of institution

- Reliability of technology

- Safety of facility

- Good appearance of facility (Hoshino, 2001)

- Disproportionate siting (Been, 1993)

- Facility siting process (Tchobanoglous, 1993) 
Table 2 Factors affecting social acceptance of SWM facilities

Personal factors

- Race

- Age and Sex

- Education

- Environmental awareness

- $\quad$ Risk perception (Slovic, 2000)
Demographic factors

- Population

- Cultural and psychological factors

- Socioeconomic factors 
Table 3 Structure of questionnaire

\begin{tabular}{|c|c|c|c|c|}
\hline $\begin{array}{c}\text { Social } \\
\text { aspects }\end{array}$ & Components & & $\begin{array}{l}\text { Question } \\
\text { No. }\end{array}$ & Items \\
\hline \multirow[t]{23}{*}{ Concern } & \multirow{13}{*}{$\begin{array}{l}\text { Impact } \\
\text { related }\end{array}$} & \multirow{4}{*}{$\begin{array}{l}\text { Pollution and } \\
\text { health effects }\end{array}$} & Q1 & Air pollution \\
\hline & & & Q2 & Water pollution \\
\hline & & & Q3 & Soil pollution \\
\hline & & & Q4 & Dioxin \\
\hline & & \multirow{2}{*}{$\begin{array}{l}\text { Damage to } \\
\text { nature }\end{array}$} & Q5 & Plant and animal \\
\hline & & & Q6 & Forest \\
\hline & & \multirow[t]{7}{*}{ Nuisance } & Q7 & Stench and noise of collection vehicles \\
\hline & & & Q8 & Traffic accidents caused by collection vehicles \\
\hline & & & Q9 & Stench and noise of facility \\
\hline & & & Q10 & Flies, rodents, crows (pests) \\
\hline & & & Q11 & Deterioration of living environment \\
\hline & & & Q12 & Decrease of property value \\
\hline & & & Q13 & Influence on farm products \\
\hline & \multirow{8}{*}{$\begin{array}{l}\text { Management } \\
\text { related }\end{array}$} & Benefit & Q14 & Convenience of facility \\
\hline & & \multirow[t]{4}{*}{ Reliability } & Q15 & Information disclosure on operation/management \\
\hline & & & Q16 & Reliability of technology \\
\hline & & & Q17 & Financial stability of facility owner \\
\hline & & & Q18 & Clear siting process \\
\hline & & \multirow[t]{3}{*}{ Cost } & Q19 & Initial cost \\
\hline & & & Q20 & Operation and management cost \\
\hline & & & Q21 & Post closure property value \\
\hline & \multirow[t]{2}{*}{ Unfairness } & & Q22 & Receiving other city's waste \\
\hline & & & Q23 & Construction of facility in the neighborhood \\
\hline \multirow[t]{6}{*}{ Attitude } & & \multirow{3}{*}{$\begin{array}{l}\text { Toward } \\
\text { construction }\end{array}$} & Q24 & Incinerator \\
\hline & & & Q25 & Landfill \\
\hline & & & Q26 & Recycling facility \\
\hline & & \multirow[t]{3}{*}{ General } & Q27 & Dislike of waste \\
\hline & & & Q28 & Concern about recycling \\
\hline & & & Q29 & Willingness to participate in planning \\
\hline \multirow{4}{*}{$\begin{array}{l}\text { Personal } \\
\text { attribute }\end{array}$} & & & Q30 & Experience of visiting an SWM facility \\
\hline & & & Q31 & Age \\
\hline & & & Q32 & Sex \\
\hline & & & Q33 & Years at current address \\
\hline
\end{tabular}

Choice for question:

Q1 - Q13 Very worried, Worried, Slightly worried, Not worried at all, Not sure

Q14 - Q21 Very important, Important, Slightly important, Not important at all, Not sure

Q22 - Q23 Very unfair, Unfair, Slightly unfair, Not unfair at all, Not sure

Q24 - Q26 In favor, Not concerned, Opposed

Q27 Disliked very much, Disliked, Not so disliked, Not disliked at all, Not sure

Q28 Very much concerned, Concerned, Slightly concerned, Not concerned, Not sure

Q29 Yes, No, Not sure

Q30 Visited, Just seen from outside, None (Type of facility was not specified in the question) 


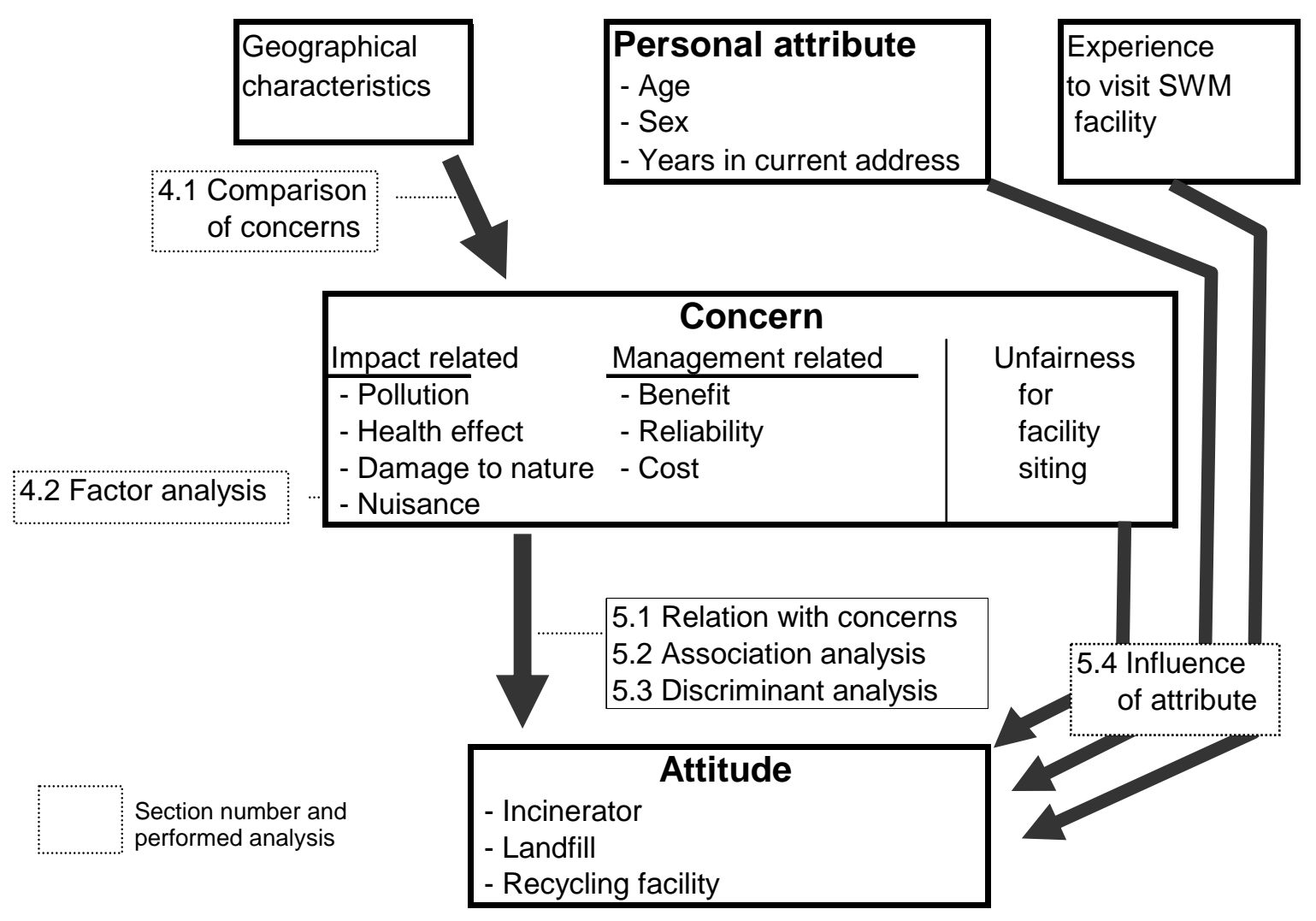

Figure 1 Structure of analysis 


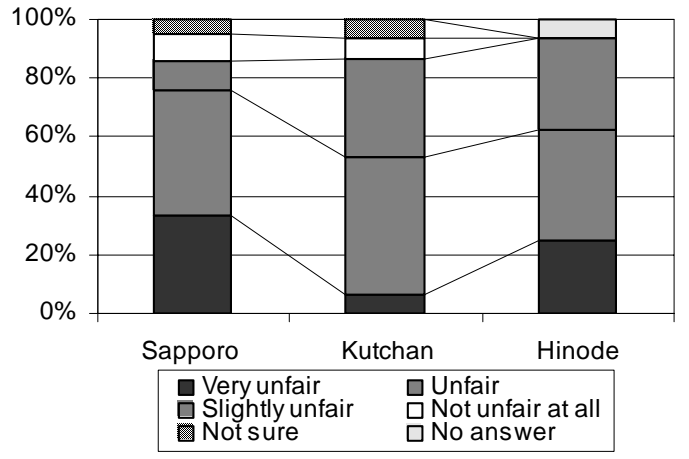

Unfairness; receving other city's waste (Q22)

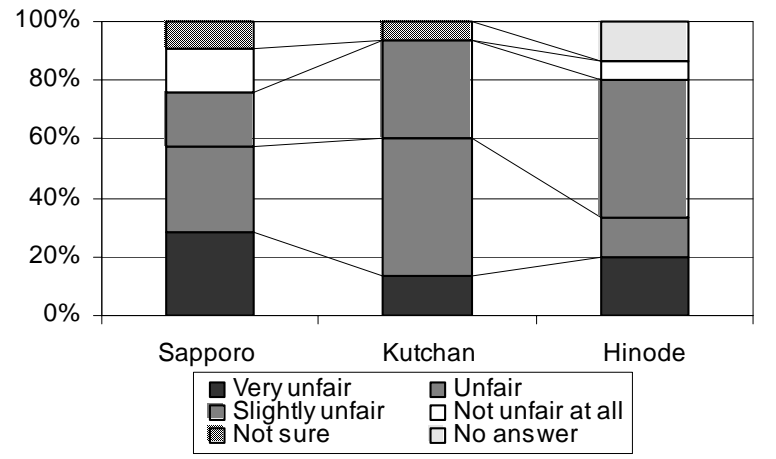

Unfairness; construction of facility in the neighborhood (Q23)

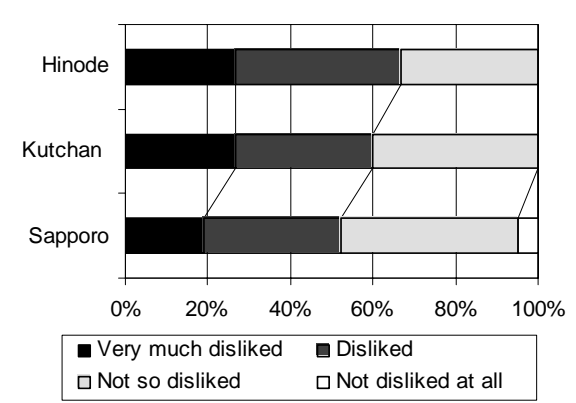

Dislike of waste (Q27)

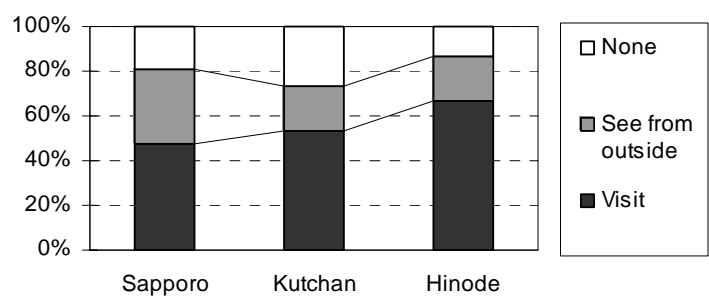

Exprerience to visit SWM facility (Q30)

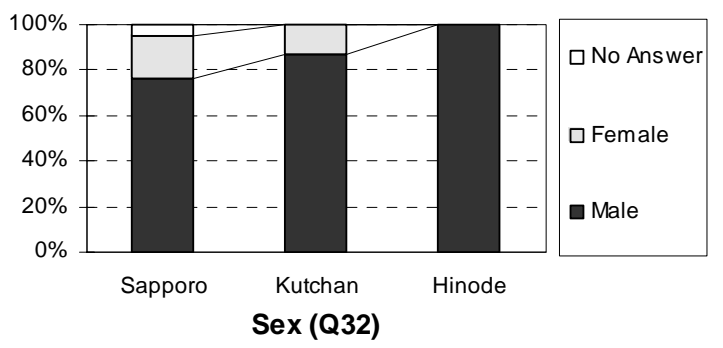

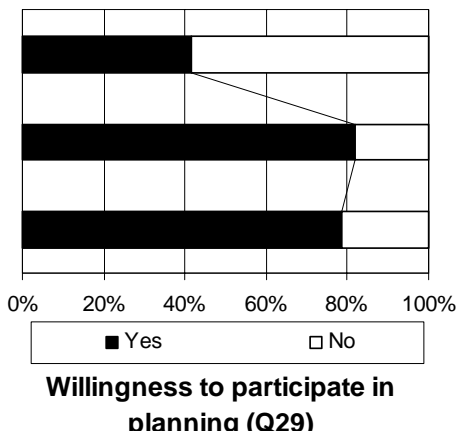

planning (Q29)

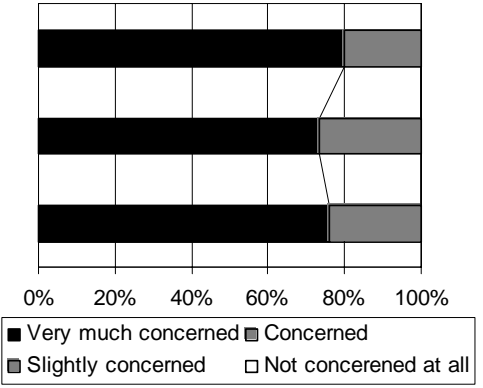

Concern about recycling (Q28)
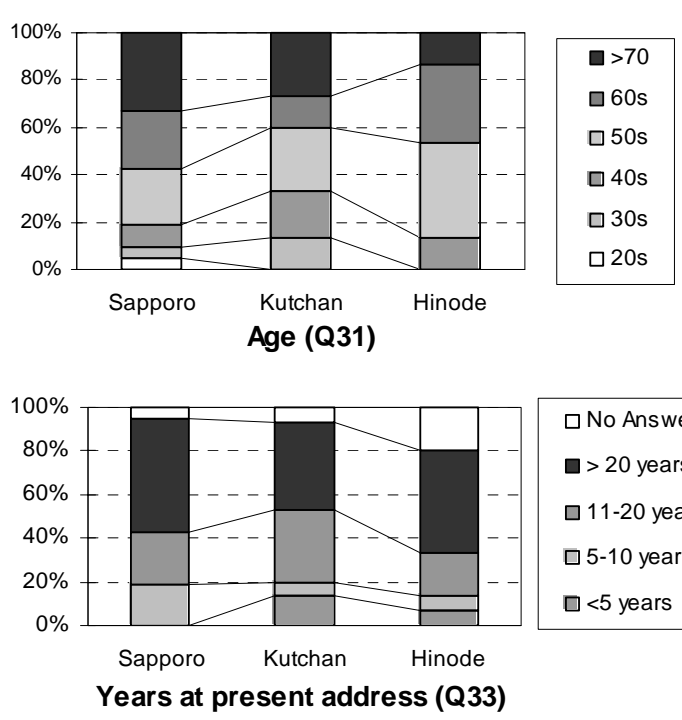

$\square$ No Answer $\square>20$ years $\square 11-20$ years $\square$ 5-10 years $\square<5$ years

Number of respondents: Sapporo 21, Kutchan 15, Hinode 15.

Figure 2 Statistics of respondents 


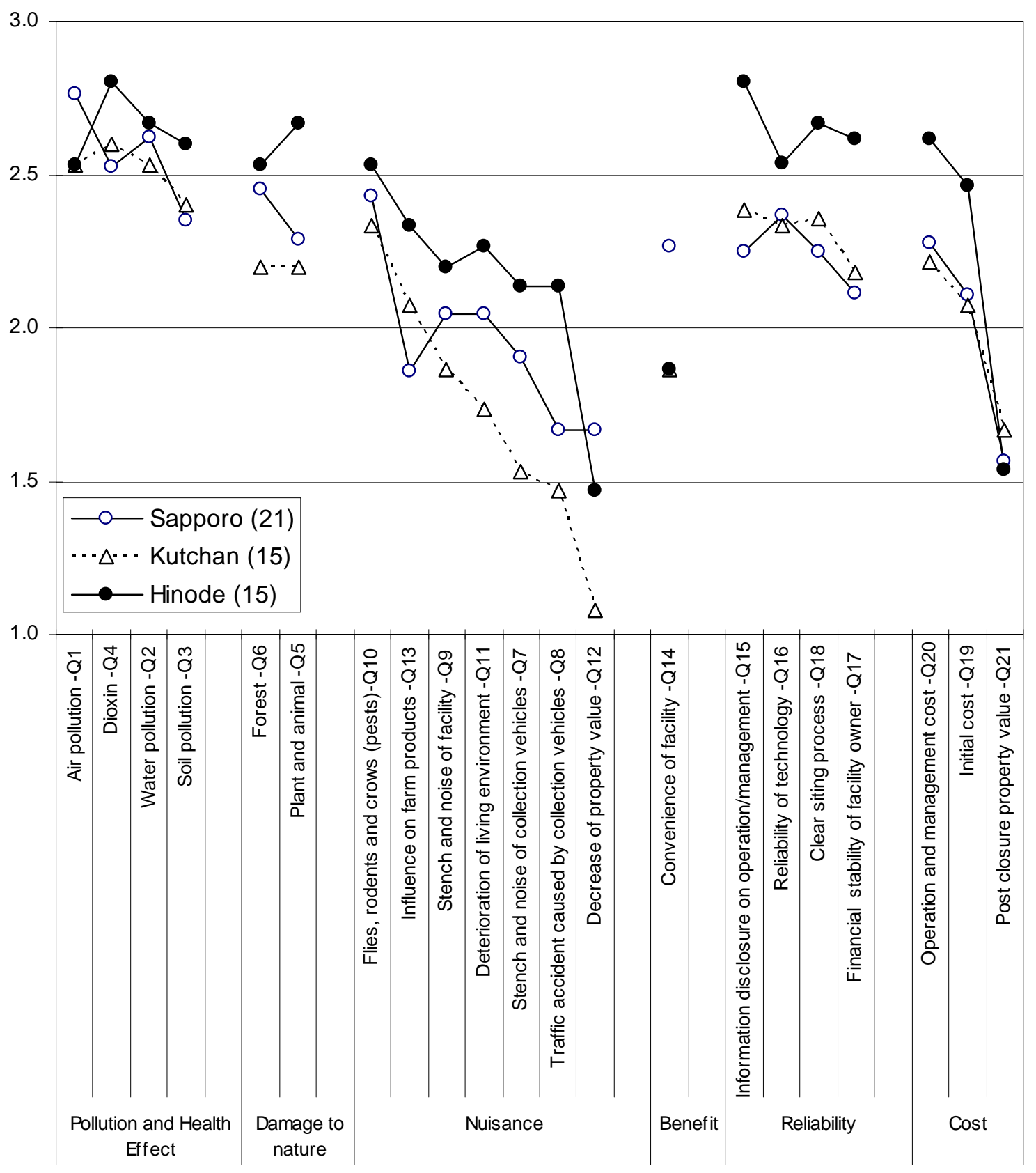

Rate for choice :

Q1 - Q13 Very worried (3), Worried (2), Slightly worried (1), Not worried at all (0)

Q14 - Q21 Very important (3), Important (2), Slightly important (1), Not important at all (0)

Figure 3 Rating of concerns 
Table 4 Principal components of concerned variables by factor analysis

\begin{tabular}{|c|c|c|c|c|c|c|}
\hline \multirow[t]{2}{*}{ Variable } & \multirow{2}{*}{$\begin{array}{l}\text { Principal } \\
\text { Component }\end{array}$} & \multicolumn{5}{|c|}{ Component } \\
\hline & & 1 & 2 & 3 & 4 & 5 \\
\hline Air pollution-Q1 & Pollution & 0.89 & 0.17 & -0.03 & 0.08 & 0.01 \\
\hline Water pollution-Q2 & & 0.88 & 0.05 & 0.11 & 0.05 & 0.09 \\
\hline Soil pollution-Q3 & & 0.74 & 0.22 & 0.36 & 0.24 & -0.09 \\
\hline Deterioration of living environment-Q11 & & 0.69 & 0.36 & 0.21 & 0.21 & 0.10 \\
\hline Dioxin-Q4 & & 0.68 & 0.27 & 0.45 & 0.18 & -0.06 \\
\hline Plant and animal-Q5 & & 0.55 & 0.49 & 0.37 & 0.08 & 0.18 \\
\hline Forest-Q6 & & 0.52 & 0.50 & 0.36 & -0.11 & 0.31 \\
\hline Flies, rodents, crows (pests)-Q10 & Nuisance & 0.28 & 0.79 & 0.23 & -0.08 & 0.23 \\
\hline Traffic accident caused by collection vehicles-Q8 & & 0.02 & 0.79 & 0.27 & 0.21 & -0.01 \\
\hline Stench and noise of facility-Q9 & & 0.45 & 0.72 & 0.19 & 0.16 & 0.22 \\
\hline Influence on farm product-Q13 & & 0.50 & 0.64 & 0.21 & 0.18 & -0.18 \\
\hline Stench and noise of collection vehicles-Q7 & & 0.44 & 0.63 & 0.13 & 0.32 & -0.03 \\
\hline Reliability of technology-Q16 & & 0.14 & 0.51 & 0.43 & 0.29 & 0.08 \\
\hline Operational and management cost-Q20 & Facility & 0.35 & 0.22 & 0.86 & 0.12 & -0.07 \\
\hline Initial cost-Q19 & management & 0.24 & 0.24 & 0.82 & 0.26 & 0.05 \\
\hline Information disclosure on operation/management-Q15 & & 0.03 & 0.34 & 0.68 & 0.14 & 0.28 \\
\hline Clear siting process-Q18 & Planning & 0.14 & 0.05 & 0.27 & 0.88 & 0.10 \\
\hline Financial stability of facility owner-Q17 & & 0.12 & 0.21 & 0.16 & 0.87 & 0.00 \\
\hline Decrease of property value-Q12 & & 0.30 & 0.42 & -0.03 & 0.54 & 0.43 \\
\hline Convenience of facility-Q14 & Merit & -0.07 & 0.34 & -0.05 & -0.05 & 0.83 \\
\hline Post closure property value-Q21 & & 0.13 & -0.27 & 0.33 & 0.30 & 0.77 \\
\hline
\end{tabular}

Method: PCA with varimax rotation, number of variable: 21 , number of respondent 32 . Significant of 0.5 was used as criterion to identify component. Variables in each principal component are sorted in the order of component.

Component loading $>0.5$

Component loading $>0.4$ 

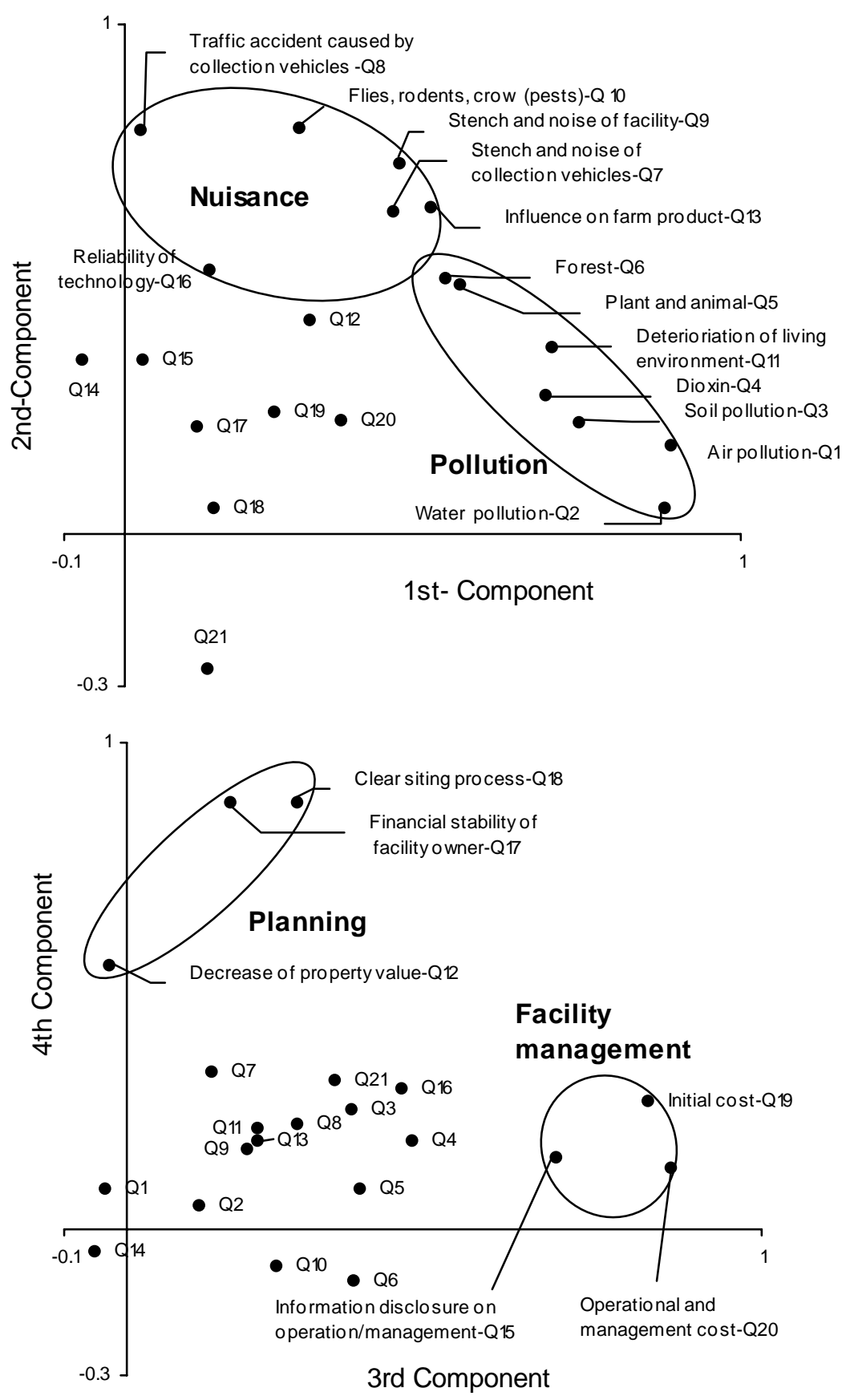

Figure 4 Plotting of component loadings 

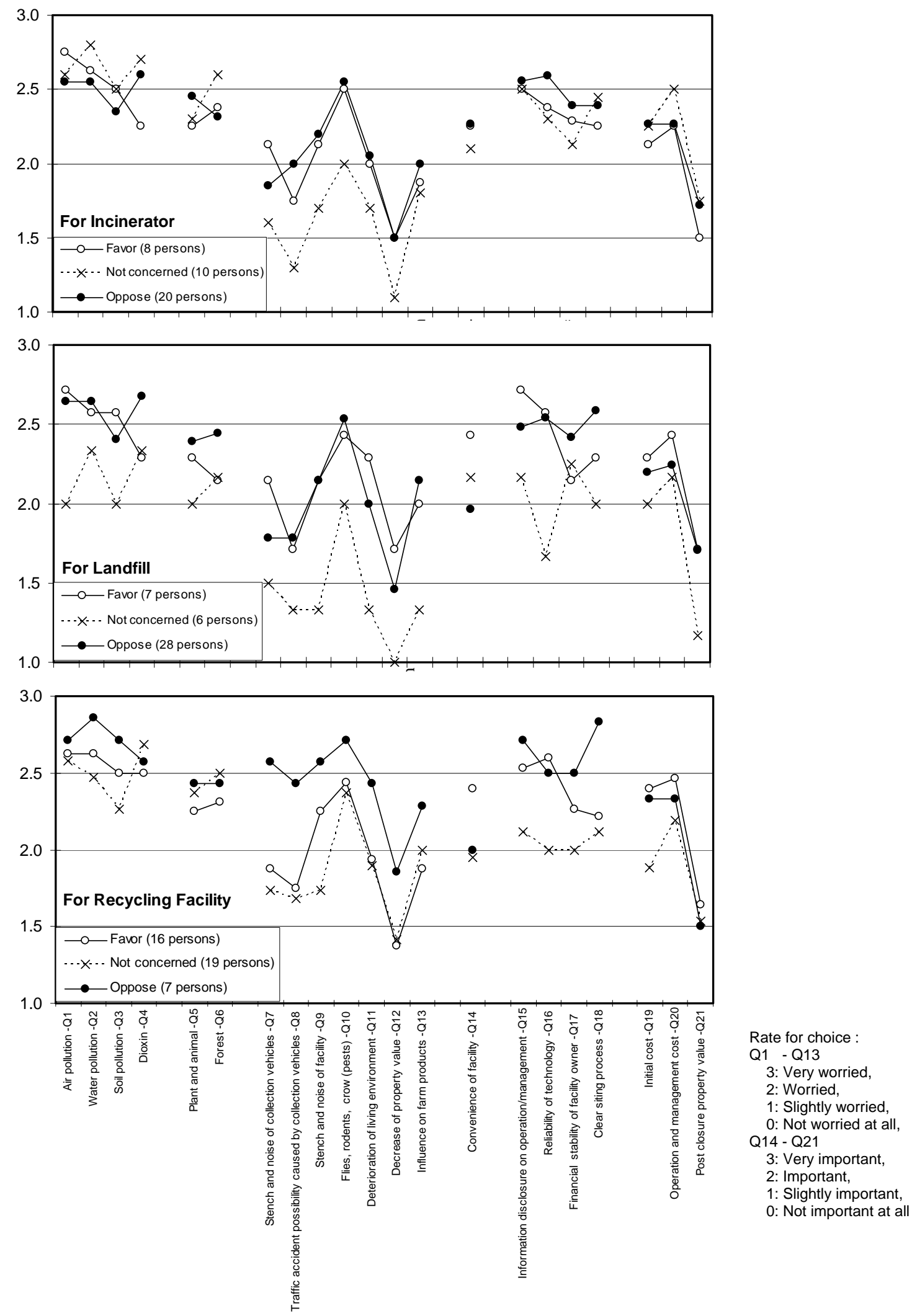

Figure 5 Rating of concerns by different attitude group to the construction of SWM facility 
Table 5 Association of concerned items and attitudes towards SWM facilities

\begin{tabular}{|c|c|c|c|c|c|c|c|c|c|c|}
\hline \multirow[t]{3}{*}{ No } & \multirow[t]{3}{*}{ Items } & \multicolumn{3}{|c|}{ Incinerator } & \multicolumn{3}{|c|}{ Landfill } & \multicolumn{3}{|c|}{ Recycling facility } \\
\hline & & \multirow{2}{*}{$\frac{\text { Chi sq. }}{\text { sig }}$} & \multicolumn{2}{|c|}{$\mathrm{GK}_{\gamma}$} & \multirow{2}{*}{$\frac{\text { Chi sq. }}{\text { sig }}$} & \multicolumn{2}{|c|}{$\mathrm{GK}_{\gamma}$} & \multirow{2}{*}{$\frac{\text { Chi sq. }}{\text { sig }}$} & \multicolumn{2}{|c|}{$\mathrm{GK} \gamma$} \\
\hline & & & coef. & sig. & & coef. & sig. & & coef. & sig. \\
\hline Q1 & Air pollution & - & 0.24 & 0.59 & - & 0.00 & 1.00 & - & 0.00 & 1.00 \\
\hline Q2 & Water pollution & - & 0.05 & 0.90 & - & -0.23 & 0.61 & - & -0.62 & 0.15 \\
\hline Q3 & Soil pollution & - & 0.00 & 1.00 & - & 0.11 & 0.80 & - & -0.40 & 0.35 \\
\hline Q4 & Dioxin & - & -0.40 & 0.34 & - & -0.39 & 0.39 & - & -0.29 & 0.52 \\
\hline Q5 & Plant and animal & - & -0.20 & 0.63 & - & 0.14 & 0.73 & - & -0.25 & 0.56 \\
\hline Q6 & Forest & - & 0.54 & 0.16 & - & 0.40 & 0.33 & - & 0.00 & 1.00 \\
\hline Q7 & $\begin{array}{l}\text { Stench and noise of } \\
\text { collection vehicles }\end{array}$ & - & 0.17 & 0.71 & - & 0.47 & 0.31 & * & -0.86 & $0.01^{* \star}$ \\
\hline Q8 & $\begin{array}{l}\text { Traffic accident caused by } \\
\text { collection vehicles }\end{array}$ & - & -0.50 & 0.27 & - & -0.24 & 0.64 & ** & -0.84 & $0.01^{\star \star}$ \\
\hline Q9 & Stench and noise of facility & - & 0.43 & 0.28 & - & 0.35 & 0.40 & - & -0.25 & 0.56 \\
\hline Q10 & Fly, rodents, crow & - & 0.05 & 0.90 & - & -0.07 & 0.86 & - & -0.29 & 0.52 \\
\hline Q11 & $\begin{array}{l}\text { Deterioration of living } \\
\text { environment }\end{array}$ & - & -0.05 & 0.90 & - & 0.54 & 0.19 & - & -0.57 & 0.14 \\
\hline Q12 & Decrease of property value & - & 0.36 & 0.44 & - & 0.61 & 0.19 & - & 0.00 & 1.00 \\
\hline Q13 & Influence on farm products & - & 0.16 & 0.71 & - & 0.25 & 0.55 & - & -0.36 & 0.38 \\
\hline Q14 & Convenience of facility & - & 0.05 & 0.90 & - & 0.36 & 0.39 & - & 0.21 & 0.65 \\
\hline Q15 & $\begin{array}{l}\text { Information disclosure on } \\
\text { operation/management }\end{array}$ & - & 0.14 & 0.74 & - & 0.69 & $0.07^{*}$ & - & -0.33 & 0.45 \\
\hline Q16 & Reliability of technology & - & -0.51 & 0.20 & - & -0.09 & 0.83 & - & 0.06 & 0.90 \\
\hline Q17 & $\begin{array}{l}\text { Financial stability of facility } \\
\text { owner }\end{array}$ & - & 0.14 & 0.75 & - & -0.22 & 0.60 & - & -0.21 & 0.65 \\
\hline Q18 & Clear siting process & - & -0.33 & 0.43 & - & -0.39 & 0.40 & - & -0.64 & 0.14 \\
\hline Q19 & Initial cost & - & -0.46 & 0.25 & - & -0.02 & 0.96 & - & -0.21 & 0.65 \\
\hline Q20 & $\begin{array}{l}\text { Operation and } \\
\text { management cost }\end{array}$ & - & -0.20 & 0.63 & - & 0.26 & 0.54 & - & -0.08 & 0.87 \\
\hline Q21 & Post closure property value & - & -0.46 & 0.34 & - & 0.21 & 0.69 & - & 0.24 & 0.68 \\
\hline
\end{tabular}

Chi sq. : Chi-square test; GK $\gamma$ : Goodman-Kruskal gamma

** significant at the $1 \%$ level, * significant at the $5 \%$ level, - not significant 


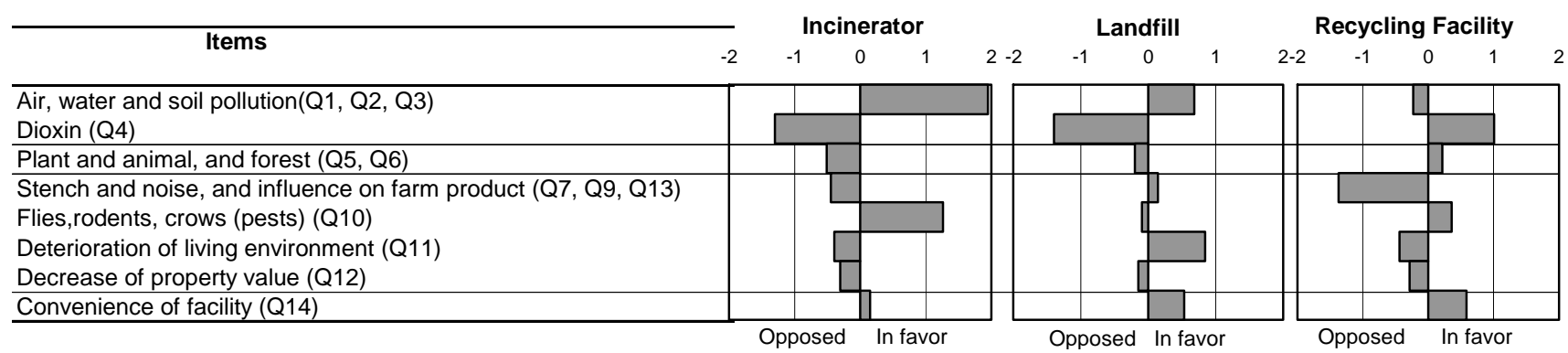

Number of data : incinerator 25, landfill 31 and recycling facility 22

Figure 6 Standardized discriminant function coefficients of discriminant functions 


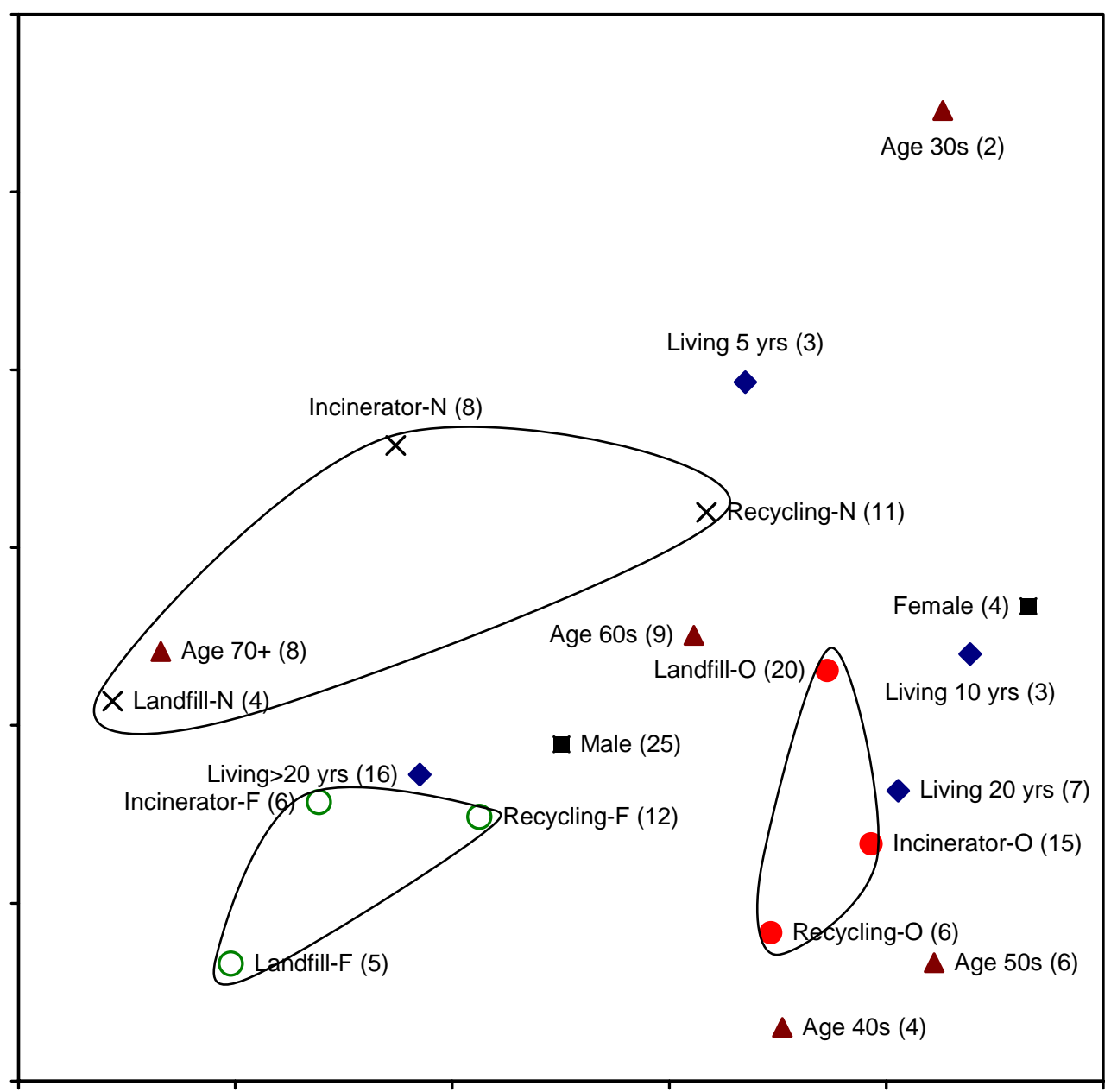

$\mathrm{O}=$ opposed, $\mathrm{N}=$ not- concerned, $\mathrm{F}=$ favor; $\quad(\quad)=$ number of respondent

29 data were used excluding "NS" (Not sure) answer and no answer for attitudes and attributes

Figure 7 Correspondence of personal attributes and attitudes toward SWM facilities 


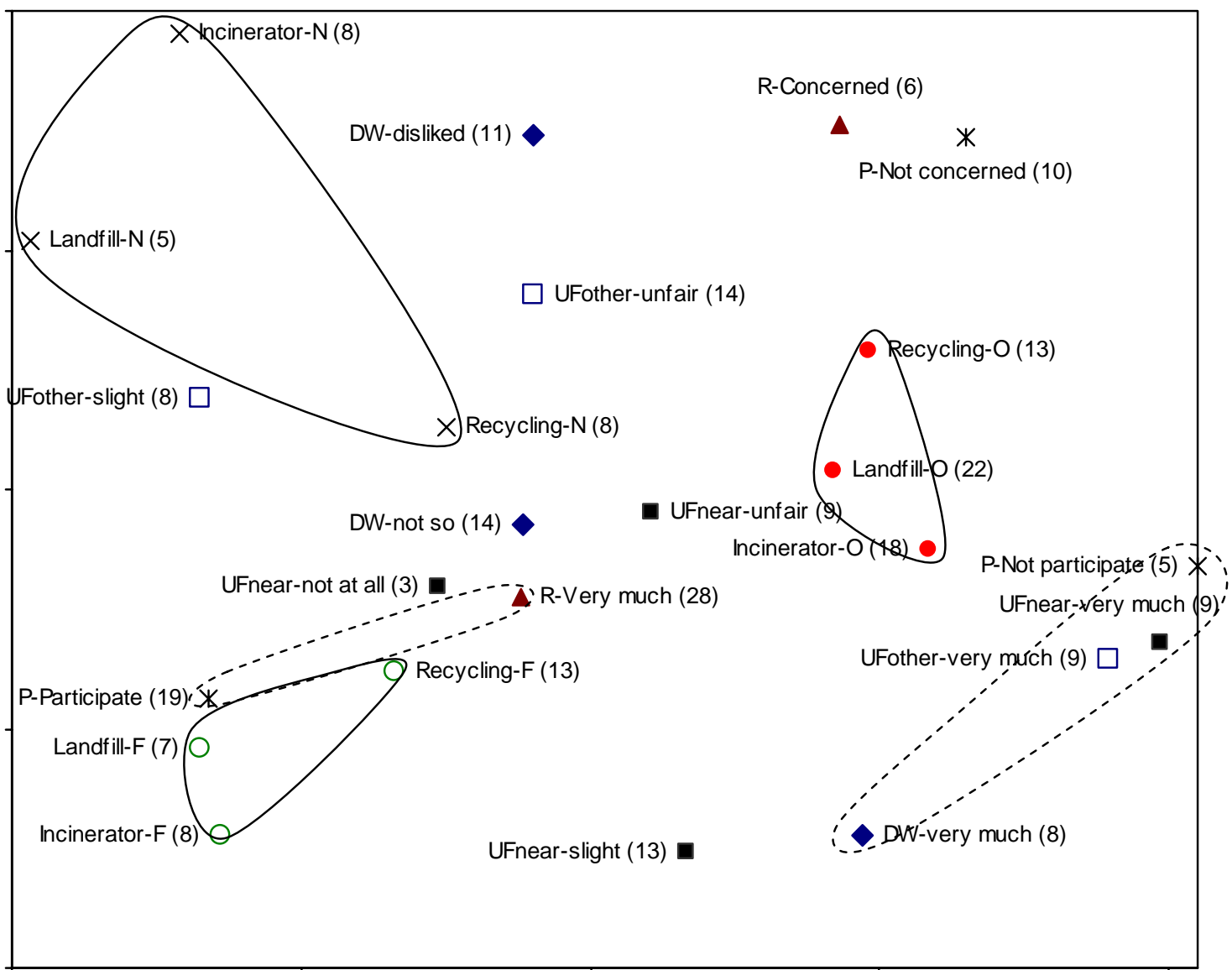

UFother = Unfairness for receiving other city's waste (Q-22); UFnear = Unfairness for construction facility in the neighborhood (Q-23); $\mathrm{DW}=$ Dislike of waste $(\mathrm{Q}-27) ; \mathrm{R}=$ concern about recycling $(\mathrm{Q}-28) ; \mathrm{P}=$ participation in planning (Q-29);

$\mathrm{O}=$ oppose, $\mathrm{N}=$ not-concerned, $\mathrm{F}=$ favor; $(\mathrm{I})$ = number of respondents

30 data were used by excluding NS (Not sure) and no answer

Figure 8 Correspondence of unfairness feeling, general attitudes and attitudes toward SWM facilities. 


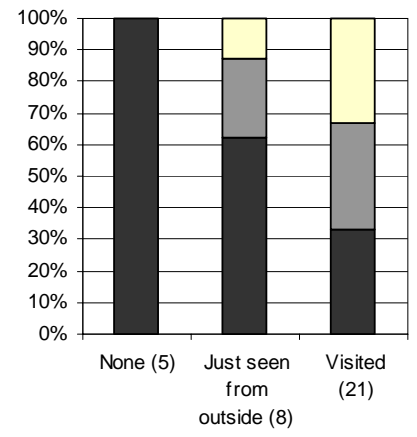

Attitude to incinerator

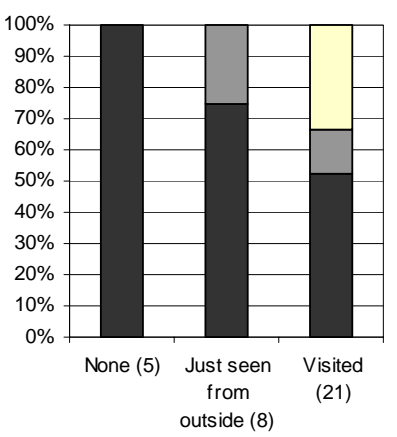

Attitude to landfill

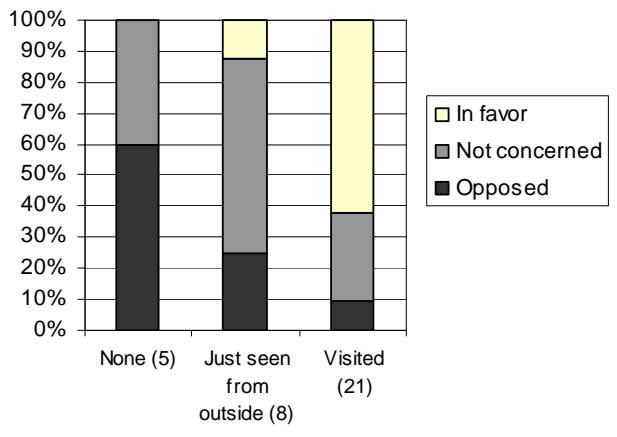

Attitude to recycling facility

( ) Number of respondents

Figure 9 Correlation of experience of visiting SWM facility with attitudes 